www.revistageintec.net

ISSN: 2237-0722

\section{GEINTEC \\ Gestäo, Inovaçã̃o e Tecnologias IIIIIIIIII!I}

\title{
PROSPECÇÃO TECNOLÓGICA DO USO DA PRATA CONTRA MICROORGANISMOS NOCIVOS EM SISTEMAS DE ÁGUA
}

\section{TECHNOLOGICAL FORECASTING OF THE USE OF SILVER AGAINST HARMFUL MICROORGANISMS IN WATER SYSTEMS}
Lucindo José Quintans-Junior ${ }^{1}$, Márcio Roberto Viana dos Santos ${ }^{2}$, Adriano Antunes de Souza Araújo $^{3}$

\footnotetext{
${ }^{1}$ Departamento de Fisiologia. Universidade Federal de Sergipe - UFS - São Cristóvão/SE - Brasil lucindo_jr@yahoo.com.br

${ }^{2}$ Departamento de Fisiologia. Universidade Federal de Sergipe - UFS - São Cristóvão/SE - Brasil marcio@infonet.com.br

${ }^{3}$ Departamento de Fisiologia. Universidade Federal de Sergipe - UFS - São Cristóvão/SE - Brasil adriasa2001@yahoo.com.br
}

\begin{abstract}
Resumo
A água, apesar de hoje ser um elemento indispensável à vida, é também uma fonte de contaminação e veículo de transmissão de doenças. As pesquisas e tecnologias realizadas para tratamento de água são inúmeras e tornam-se uma preocupação constante dos pesquisadores. Nesse contexto, um elemento estudado e com seus efeitos antimicrobianos bem conhecidos é a prata (Ag). Assim, esse estudo objetivou a realização de uma prospecção tecnológica nas bases patentearias nacional e mundial, a fim de caracterizar as pesquisas que estão sendo realizadas com o uso da prata nesse meio. O estudo mostrou um acentuado avanço tecnológico na área de tratamento de água, sendo os Estados Unidos o país que mais deposita patentes. Entretanto, quando a pesquisa refere-se à tratamento de água com prata, o número de patentes é extremamente reduzido, tornando o seu uso uma lacuna tecnológica a ser explorada.
\end{abstract}

Palavras-chave: prata, microorganismos, água.

\begin{abstract}
The water, though today is an element essential to life, is also a source of contamination and vehicle of disease transmission. The research and technologies used for water treatment are numerous and become a constant concern of researchers. In this context, one element studied and
\end{abstract}


its antimicrobial effects is well known silver (chemical element). Thus, this study aimed to carry out a survey patented technology in national and global patent basis in order to characterize the research being carried out with the use of silver in it. The study showed a marked technological advance in the field of water treatment, and the United States the country that puts more patents. However, when the research relates to water treatment with silver, the number of patents is extremely low, making its use a technology gap to be exploited.

Key-words: silver, microorganisms, water.

\section{Introdução}

A água é um dos elementos indispensáveis à vida, sendo uma das principais substâncias ingeridas pelo ser humano (OKURA; SIQUEIRA, 2005; NETO et al., 2006). A água doce corresponde a $1 \%$ de toda a água do planeta e, em seu estado natural, representa um dos componentes mais puros, porém esta característica vem se alterando e hoje ela é um importante veículo de transmissão de inúmeras doenças (REIS; HOFFMANN, 2006).

As ações da vigilância sanitária tais como, por exemplo, o controle da qualidade da água para o consumo humano, são de suma importância, assessorando quanto à necessidade, qualidade e promoção de medidas de intervenção, sendo preventivas ou corretivas, garantindo água de boa qualidade para o consumo (TEIXEIRA, 2005). Dentre as alternativas encontradas para tratar essa finalidade, encontra-se o uso da prata $(\mathrm{Ag})$, a qual possui efeito antimicrobiano bem conhecido.

Asssim, o presente estudo de prospecção tecnológica objetivou verificar os avanços tecnológicos relativos ao uso da prata no tratamento de água, em bases patentearias.

\section{Metodologia}

Essa prospecção tecnológica foi desenvolvida a partir da consulta ao Banco de dados do Instituto Nacional de Propriedade Industrial (INPI) do Brasil e na base da Organização Mundial da Propriedade Intelectual (World Intellectual Property Organization - WIPO). Essas fontes foram utilizadas pela abrangência do acervo e gratuidade de acesso.

A pesquisa foi realizada com as palavras-chave microorganismos (microorganisms), prata (silver) e água (water), todas sem truncagem, no campo "resumo" no caso do INPI e no campo "front page", no caso da WIPO.

Os documentos encontrados foram computados individualmente, a fim de caracterizar o avanço tecnológico dessas patentes considerando o ano de depósito, Classificação Internacional de 
Patentes (CIP) e país de depósito. As limitações referentes a período de sigilo foram respeitadas. O levantamento foi realizado em agosto de 2011.

\section{Resultados e discussão}

Inicialmente a pesquisa apontou, conforme a Tabela 1, 172 documentos na base nacional e 752 documentos na base mundial. Em relação às palavras-chave, microorganismos and água no campo resumo para INPI e no campo front page para a WIPO apresentou, respectivamente 163 e 695 documentos. Substituindo a palavra-chave água por prata os documentos foram reduzidos significativamente, e juntando-se todas as palavras-chave na mesma busca a pesquisa teve um decréscimo para 12 documentos.

Tabela 1. Total de depósitos de patentes pesquisadas nas bases da WIPO e INPI.

\begin{tabular}{llll}
\hline Palavras-chave & INPI & WIPO & TOTAL \\
\hline Microorganismos and água & 163 & 695 & $\mathbf{8 5 8}$ \\
Microorganismos and prata & 7 & 47 & $\mathbf{5 4}$ \\
Microorganismos and prata and água & 2 & 10 & $\mathbf{1 2}$ \\
TOTAL & $\mathbf{1 7 2}$ & $\mathbf{7 5 2}$ & \\
\hline
\end{tabular}

Fonte: Autoria própria (2011)

Dos documentos encontrados no INPI referente às palavras-chave microorganismos and água, verifica-se na Figura 1 que o maior número de depósitos encontra-se na classificação C02F, a qual refere-se a tratamento de água, seguido de $\mathrm{A} 01 \mathrm{~N}$, a qual refere-se a conservação de corpos de seres humanos ou animais ou plantas ou partes dos mesmos.

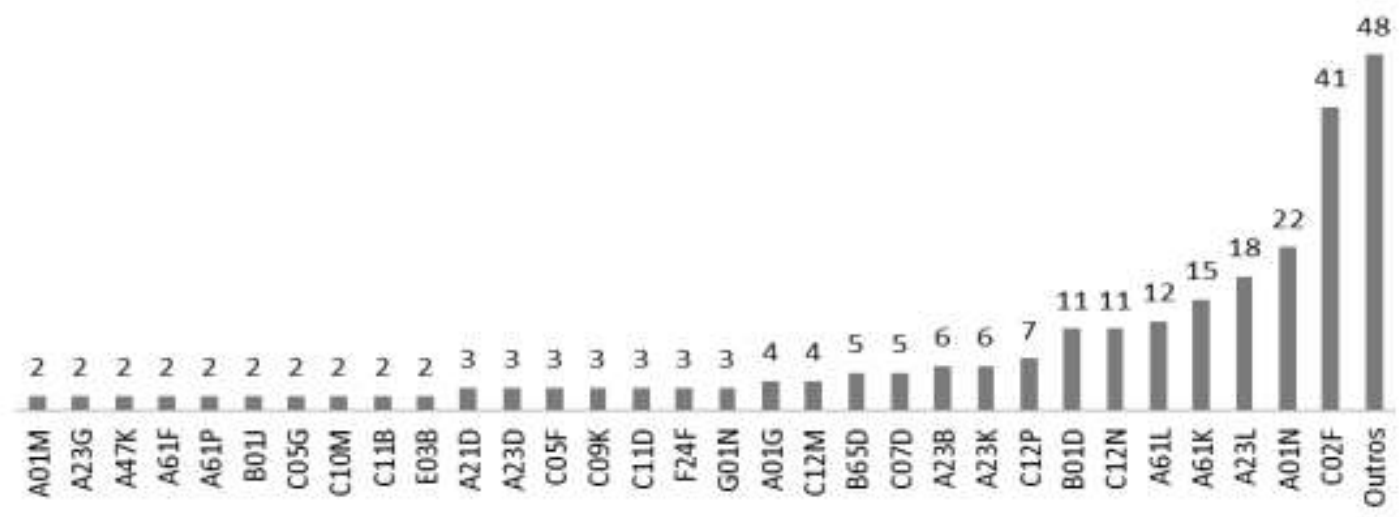

Figura 1. Distribuição por CIP dos depósitos encontrados no banco de dados nacional.

Fonte: Autoria própria (2011) 
Com relação ao número de depósitos por ano, percebe-se um aumento de depósitos de patentes a partir de 1999 até o ano de 2004, chegando a uma média anual de 14 depósitos (Figura 2).

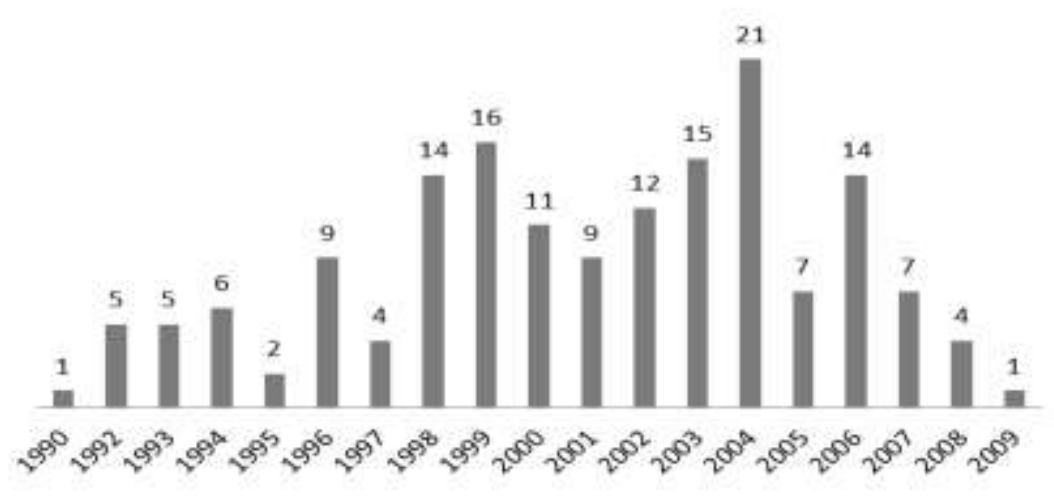

Figura 2. Pedidos internacionais por ano de publicação no banco nacional.

Fonte: Autoria própria (2011)

Os países de origem desses documentos são Brasil e Estados Unidos com 60 e 59 pedidos, respectivamente, conforme Figura 3.

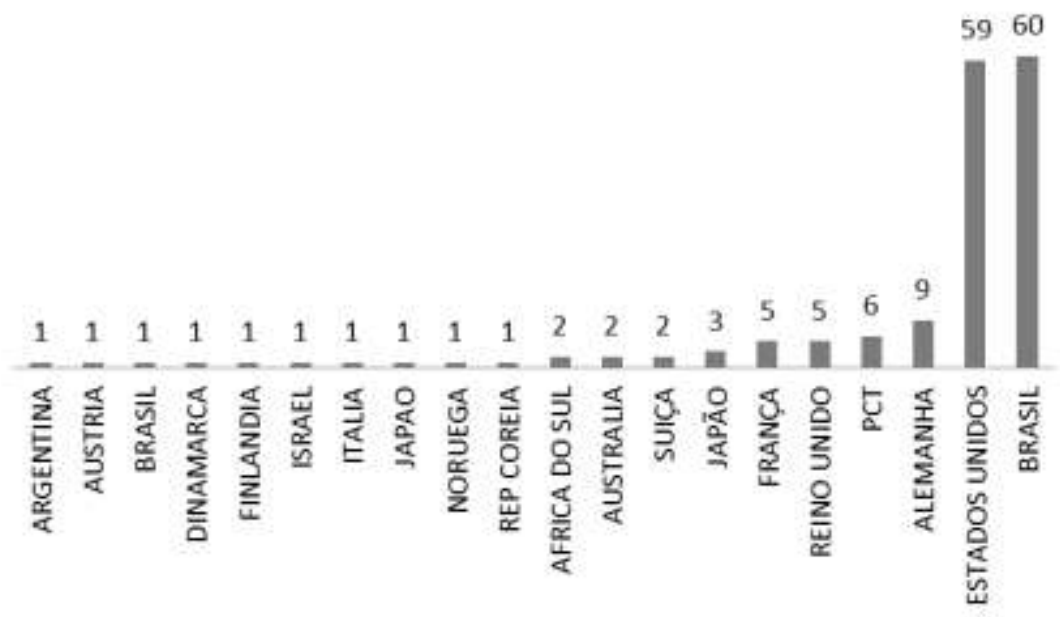

Figura 3. Patentes depositadas no banco nacional, classificadas quanto ao país de prioridade unionista.

Fonte: Autoria própria (2011)

Realizando a prospecção com as palavras-chave microorganismos and prata o número de documentos reduziu significativamente. Encontrou-se apenas 7 documentos, dos quais a maioria, segundo as Figuras 4, 5 e 6, são classificados em A01N e B01D; os anos de maior publicação são 2005 e 2007 e o país com maior número de depósitos é o Brasil. 


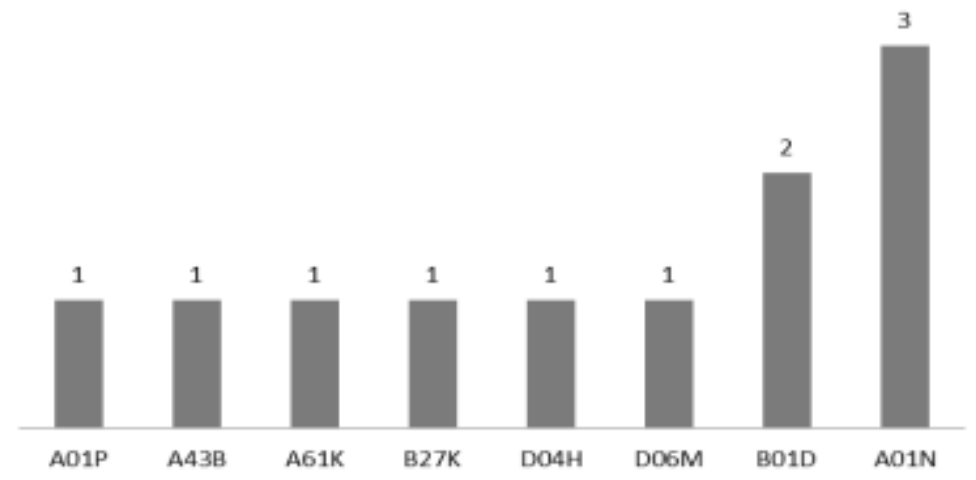

Figura 4. Distribuição por CIP dos depósitos encontrados no banco de dados nacional.

Fonte: Autoria própria (2011)

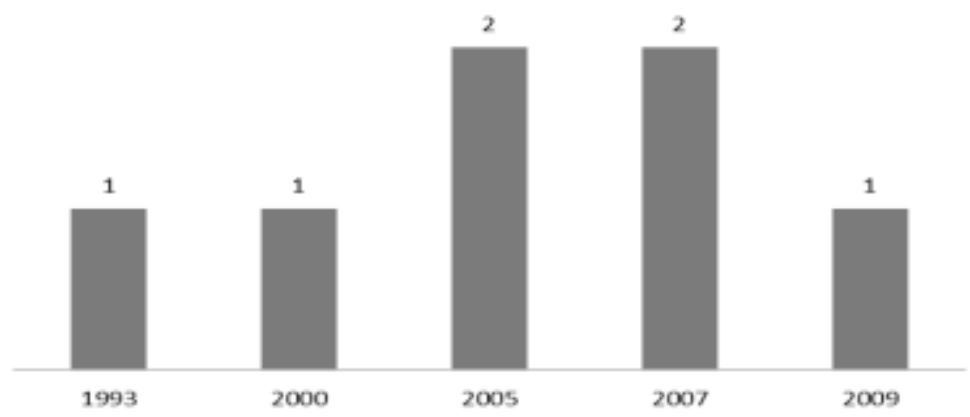

Figura 5. Pedidos internacionais por ano de publicação no banco nacional.

Fonte: Autoria própria (2011)

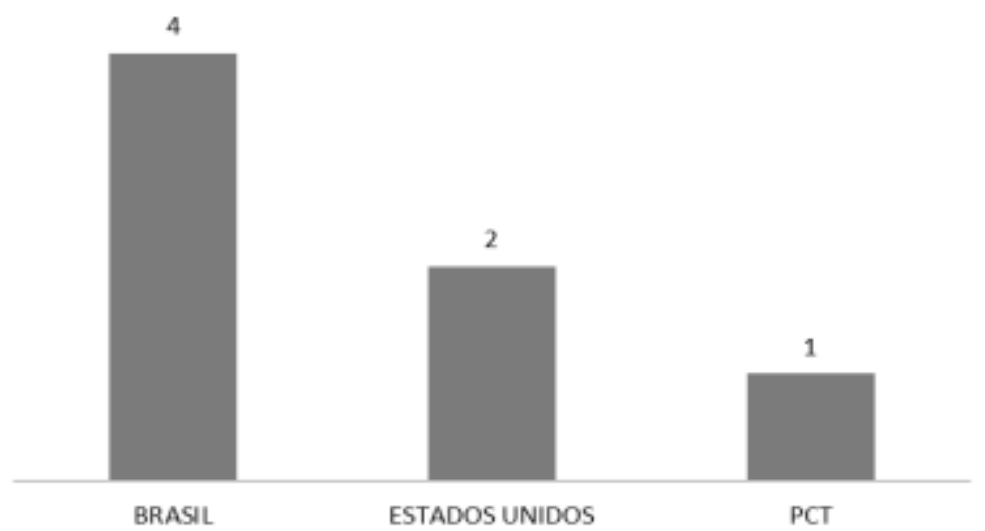

Figura 6. Patentes depositadas no banco nacional, classificadas quanto ao país de prioridade unionista.

Fonte: Autoria própria (2011)

Por fim, a pesquisa do banco nacional foi refinada com a utilização das três palavras-chave: microorganismos and água and prata, onde encontrou-se apenas dois documentos. Esses 
documentos referem-se a modelos de utilidade entitulados "Torneira filtro purificadora d'água" e "Disposição construtiva aplicada em purificador de água". Estão classificados como B01D e foram depositados no ano de 1993 e 2005, respectivamente.

Em um segundo momento, a prospecção foi efetuada no banco mundial, onde encontrou-se 695 documentos para as palavras-chave: microorganisms and water. Conforme as Figuras 7, 8 e 9, podemos analisar que a maior parte dos documentos está classificada em C02F, seguido de A01N. Observa-se também que houve uma ascensão no número de depósitos a partir de 2005, tendo um pico máximo em 2010, e, claramente, o país detentor do numero de pedidos de patentes é os Estados Unidos.

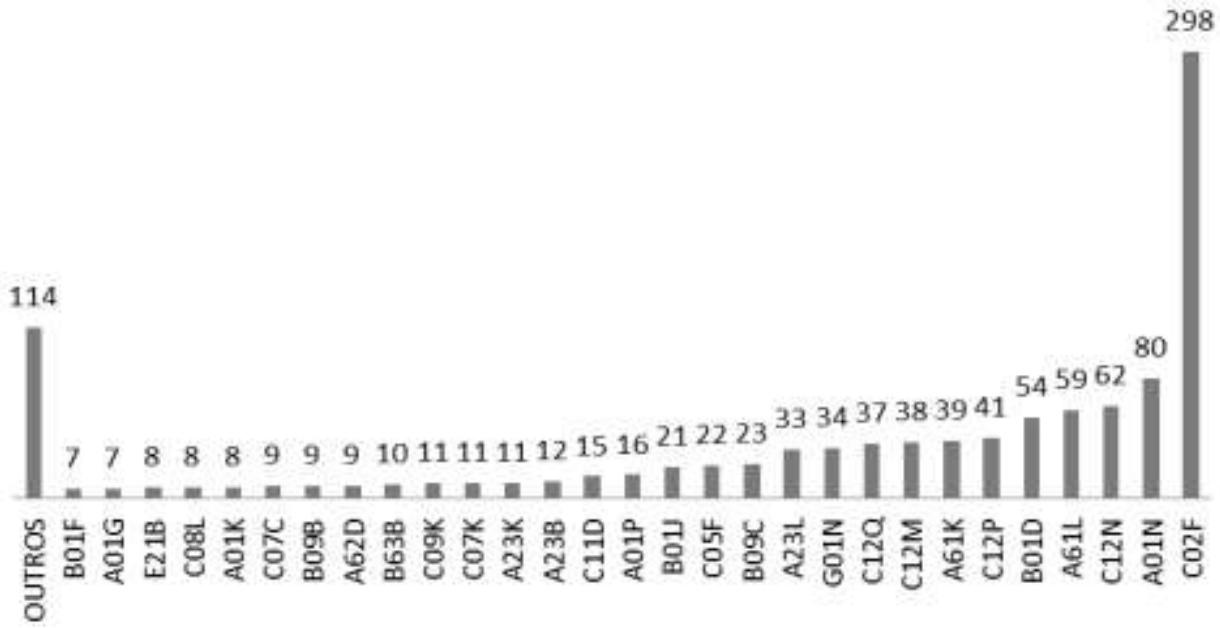

Figura 7. Distribuição por CIP dos depósitos encontrados no banco de dados mundial.

Fonte: Autoria própria (2011)

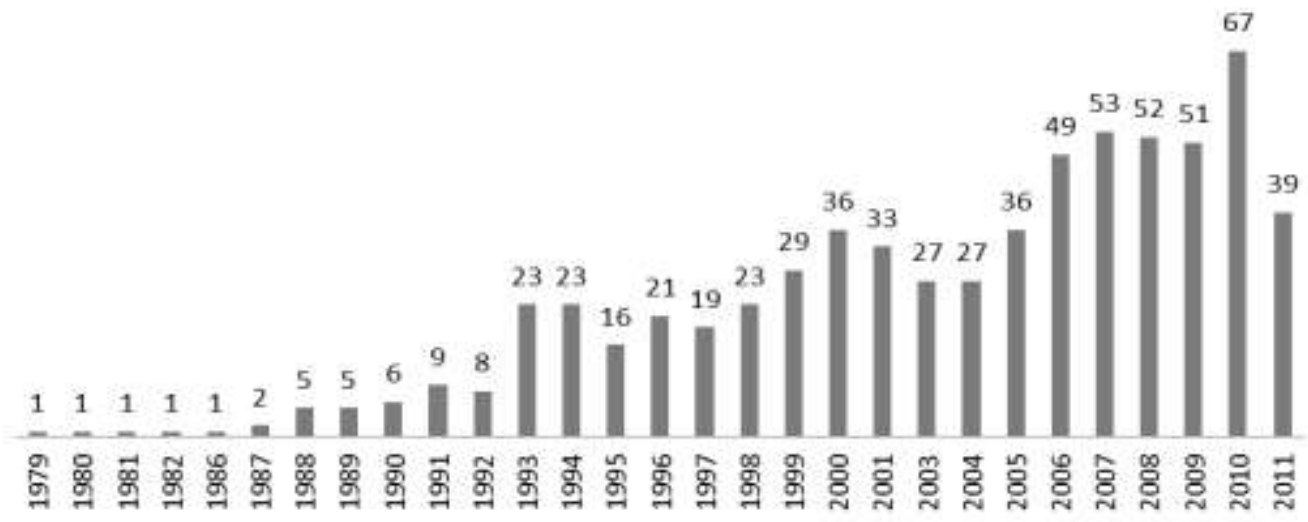

Figura 8. Pedidos internacionais por ano de publicação no banco mundial.

Fonte: Autoria própria (2011) 


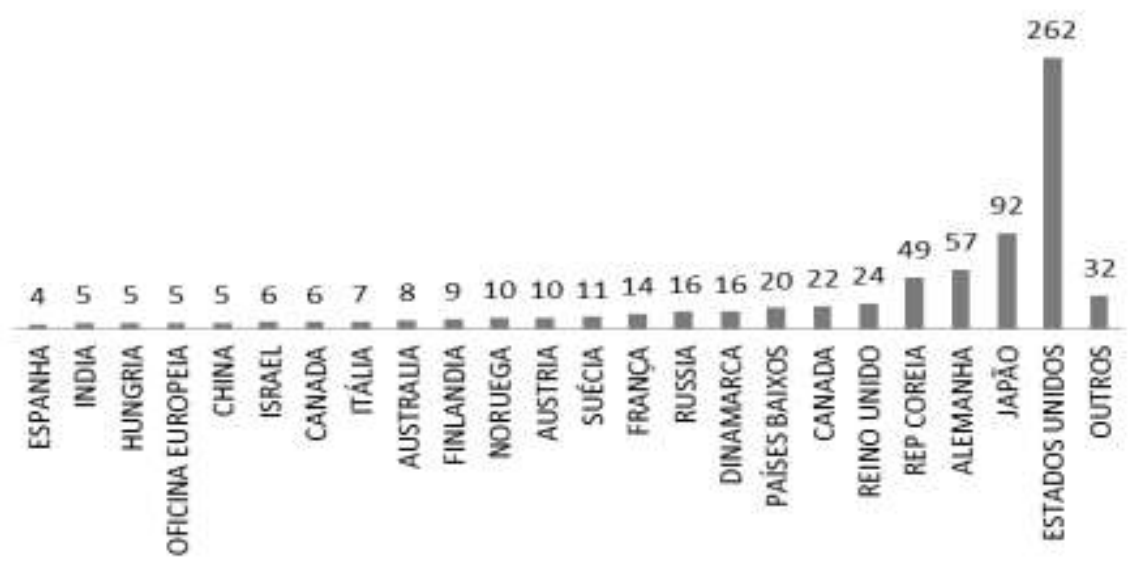

Figura 9. Patentes depositadas no banco mundial, classificadas quanto ao país de prioridade unionista.

Fonte: Autoria própria (2011)

Posteriormente, mudando a palavra-chave water por silver (microorganisms and silver), observa-se uma redução no número de depósitos para 47. Destes, conforme Figuras 10, 11 e 12, estão classificados, a sua maioria, em $\mathrm{A} 01 \mathrm{~N}$, seguido de $\mathrm{A} 61 \mathrm{~K}$, dentre outros. O maior número de depósitos foi realizado em 2009, pelos Estados Unidos.

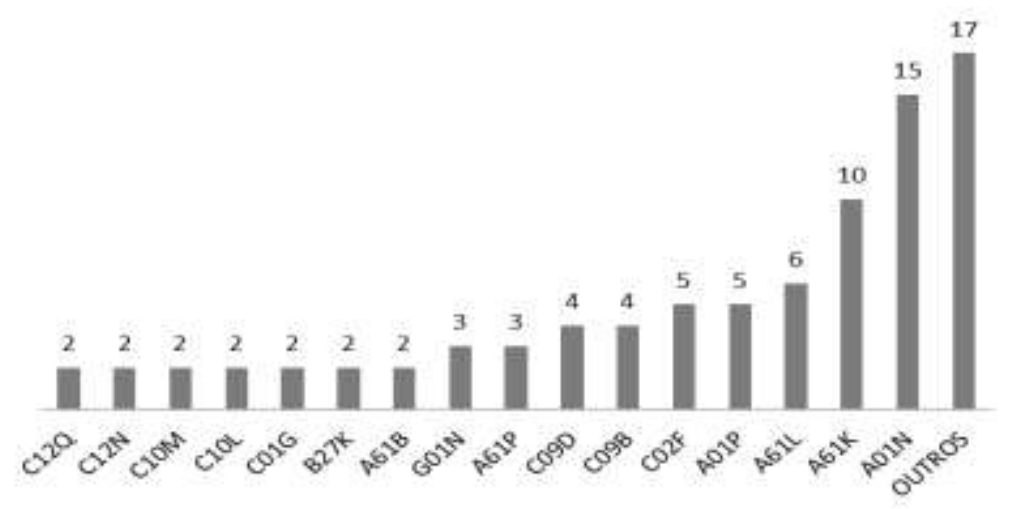

Figura 10. Distribuição por CIP dos depósitos encontrados no banco de dados mundial.

Fonte: Autoria própria (2011)

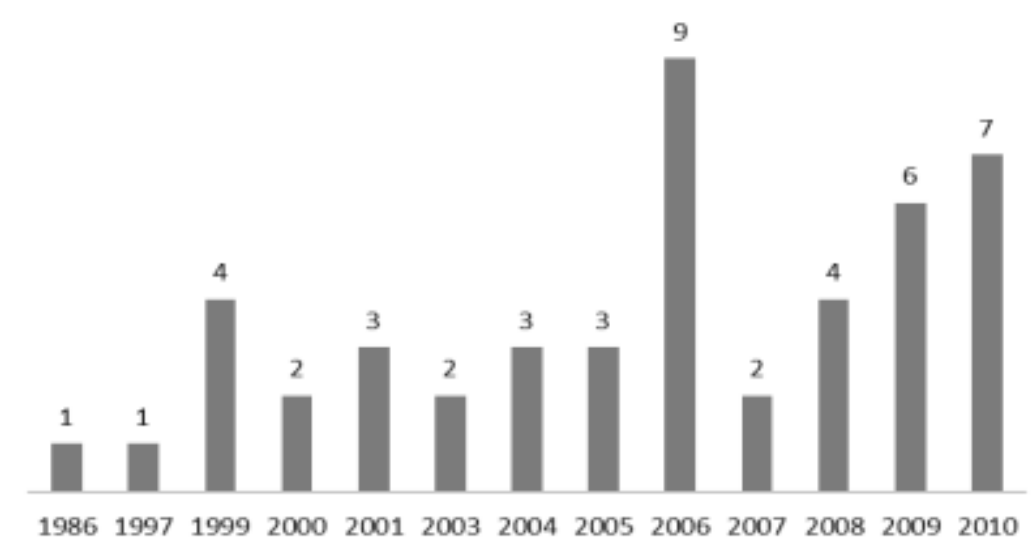

Figura 11. Pedidos internacionais por ano de publicação no banco mundial. 


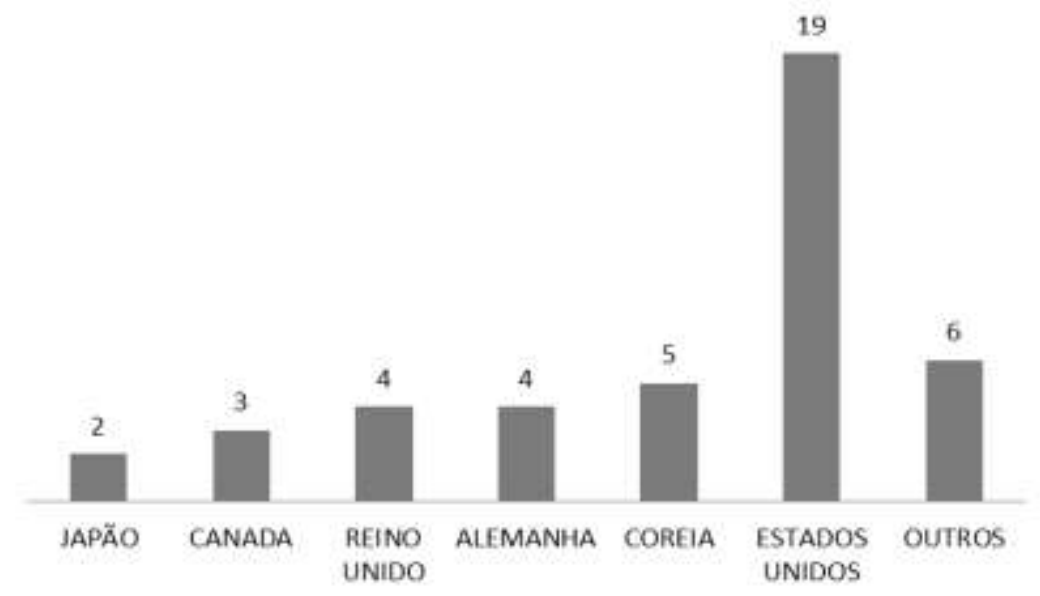

Figura 12. Patentes depositadas no banco mundial, classificadas quanto ao país de prioridade unionista.

Fonte: Autoria própria (2011)

Refinando-se mais ainda a prospecção, pesquisou-se pelas palavras-chave microorganisms and water and silver, e foram encontrados apenas 10 documentos publicados. Apesar do número de depósitos ser baixo, não tendo uma variação muito significativa entre os documentos, o perfil foi mantido. Nas Figuras 13, 14 e 15 observa-se que a maior parte dos depósitos é classificada em C02F e A01N, depositados nos anos de 1999, 2006 e 2008 e os países que se destacam são Estados Unidos e Alemanha.

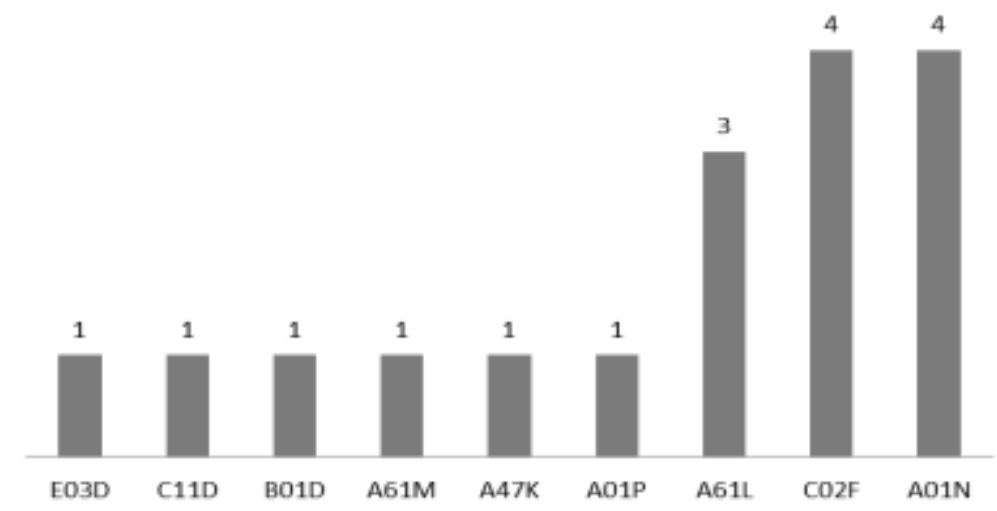

Figura 13. Distribuição por CIP dos depósitos encontrados no banco de dados mundial.

Fonte: Autoria própria (2011) 


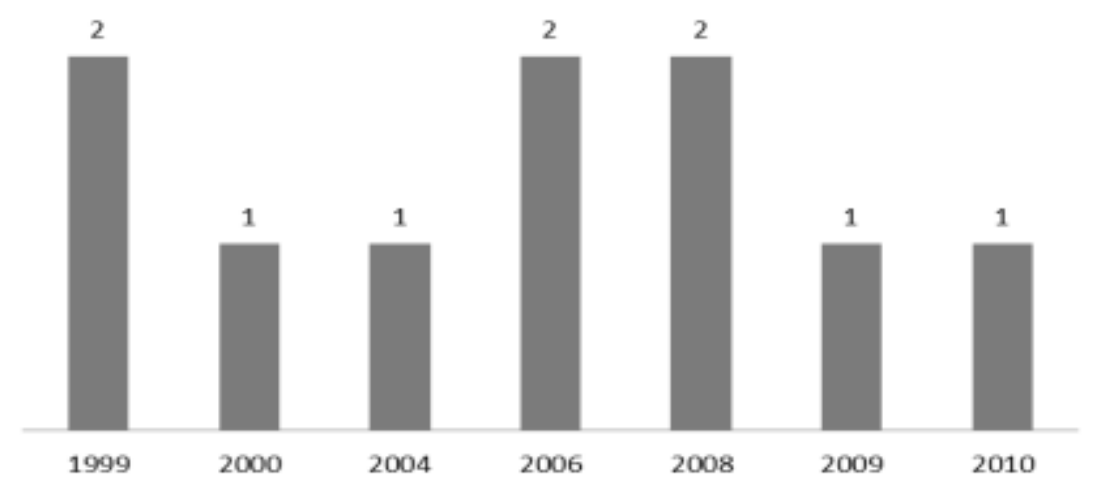

Figura 14. Pedidos internacionais por ano de publicação no banco mundial.

Fonte: Autoria própria (2011)

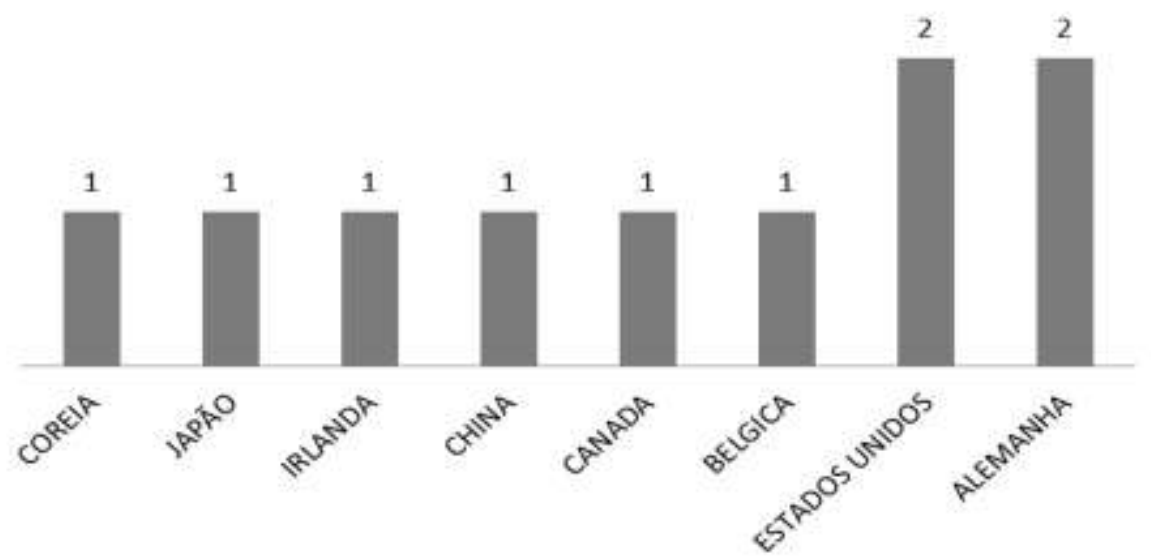

Figura 15. Patentes depositadas no banco mundial, classificadas quanto ao país de prioridade unionista.

Fonte: Autoria própria (2011)

\section{Conclusão}

Com os resultados obtidos nesse estudo, concluímos que, tratando-se de métodos para tratamento de água, existe um acentuado avanço tecnológico, sendo os Estados Unidos encontrado no ranking de países depositantes. No entanto, refinando a pesquisa com o acréscimo da palavra-chave prata, poucos documentos foram encontrados. A prospecção de patentes nos dá uma visão de como avaliar uma determinada tecnologia e qual a lacuna tecnológica a ser explorada. Assim, segure-se que o uso da prata para tratamento de água pode ser um bom campo para pesquisa e desenvolvimento de inovações tecnológicas. 


\section{Agradecimento}

Agradecemos a doutoranda Mairim Russo Serafini pelo auxílio na prospecção de patentes no INPI e no WIPO e na elaboração do artigo.

\section{Referências}

OKURA, M. H.; SIQUEIRA, K. B. Enumeração de coliformes totais e coliformes termotolerantes em água de abastecimento e de minas. Revista Higiene Alimentar, São Paulo, v. 19, n. 135, p. 8691, set. 2005.

REIS, J. A.; HOFFMANN, P.; HOFFMANN, F. L. Ocorrência de bactérias aeróbias mesófilas, coliformes totais, fecais, e Escherichia coli, em amostras de águas minerais envasadas, comercializadas no município de São José do Rio Preto, SP. Revista Higiene Alimentar, São Paulo, v. 20, n. 145, p. 109-116, out. 2006.

NETO, A. F.; SILVA, J. L.; MOURA, G. J. B.; CALAZANS, G. M. T. Avaliação da qualidade da água potável de escolas públicas do Recife, PE. Revista Higiene Alimentar, São Paulo, v. 20, n. 139, p. 80-82, mar. 2006.

TEIXEIRA, J. C. Vigilância da qualidade da água para consumo humano - utopia ou realidade? Estudo de caso: Juiz de Fora - MG. Associação Brasileira de Engenharia Sanitária e Ambiental, Rio de Janeiro, p. 1-4, 2005. 